\title{
Translucent yttrium aluminum garnet: Microwave-assisted route to synthesis and processing
}

\author{
M. Panneerselvam, ${ }^{\text {a) }}$ G.N. Subanna, ${ }^{\text {b) }}$ and K.J. Rao ${ }^{\text {a),c) }}$ \\ Solid State and Structural Chemistry Unit and Materials Research Center, Indian Institute of Science, \\ Bangalore-560012, India
}

(Received 22 March 2001; accepted 30 July 2001)

\begin{abstract}
A novel and fast microwave route is described for the synthesis of yttrium aluminum garnet (YAG) and for its sintering to translucent bodies. Precursor was made by microwave decomposition (20 min) of aluminum tri-sec-butoxide and yttrium nitrate dissolved in ethyl acetate. The precursor, conventionally calcined at $1000{ }^{\circ} \mathrm{C}(1 \mathrm{~h})$, was sintered in microwave using $\mathrm{SiC}$ as secondary heater for just $35 \mathrm{~min}$. Resulting translucent YAG has a microhardness $\left(H_{\mathrm{V}}\right)$ of $18.1 \mathrm{GPa}$ and fracture toughness $\left(K_{\mathrm{IC}}\right)$ of $4.3 \mathrm{MPa} \mathrm{m}{ }^{1 / 2}$. A $0.86-\mathrm{mm}$-thick sintered pellet exhibits approximately $45 \%$ transmission for 520-nm radiation. The entire microwave process requires less than $3 \mathrm{~h}$.
\end{abstract}

Yttrium aluminum garnet $\left(\mathrm{Y}_{3} \mathrm{Al}_{5} \mathrm{O}_{12}, \mathrm{YAG}\right)$ is a technologically important oxide ceramic. It is used as a host for lasers and for phosphors of high resolution and also as a coating on electronic devices. It is chemically stable at high temperatures. ${ }^{1-4}$ Because of its proven technological potential, several chemical routes have been developed for its synthesis. ${ }^{5-7}$ Sinterability of the YAG powders obtained from the various chemical routes has also been examined. ${ }^{6,8}$ Sintering requires temperatures of the order of $1600-1800^{\circ} \mathrm{C}$ and longer sintering times of the order of several hours. ${ }^{8-10}$ Translucent YAG has been made by sintering at very high temperatures in vacuum and by addition of sintering aids. ${ }^{6,9}$ Both the preparative and sintering processes now known are slow. In this communication, we report a novel microwave route that has well-known advantages. ${ }^{11-18}$

It was established by Warshaw and Roy ${ }^{19}$ that $\mathrm{YAG}$ is the most stable phase in the $\mathrm{Y}_{2} \mathrm{O}_{3}-\mathrm{Al}_{2} \mathrm{O}_{3}$ phase diagram, which has since been repeatedly confirmed. ${ }^{20}$ De With sintered YAG to almost theoretical density and obtained a translucent product at a temperature of $1750{ }^{\circ} \mathrm{C}$ using $\mathrm{SiO}_{2}$ and $\mathrm{MgO}$ as sintering aids. ${ }^{9}$ This was followed by a spate of activities in quest of methods for producing YAG powders that are sinterable at lower temperatues. Gowda $^{21}$ reported a sol-gel process where use is made of yttrium acetate and aluminum alkoxide and showed that the resulting amorphous gels decomposed at about $800{ }^{\circ} \mathrm{C}$ giving rise to the fine powders of monophasic

\footnotetext{
a) Solid State and Structural Chemistry Unit.

${ }^{b)}$ Materials Research Center.

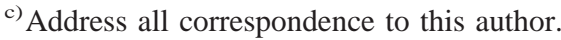

YAG. Fine powders YAG have also been made by combustion synthesis, ${ }^{22}$ where urea and carbohydrazide are used as media for holding the reactants and for triggering the reaction. In the glycothermal method ${ }^{23} 1,4-$ butanediol is used as medium for dissolving aluminum isopropoxide and yttrium acetate. In a somewhat similar procedure use is made of polyols such as glycerol. ${ }^{24}$ Citrates, nitrates, etc., ${ }^{5,7}$ have also been used as starting materials. The objective in all these methods has been to obtain an initial sol with atomic level mixing of the reactants, so as to drive the decomposition and crystallization processes leading to the YAG at as low a temperature as possible.

Preparation of translucent YAG bodies, in the present approach, consists of three stages. In the first stage aluminum tri-sec-butoxide (Merck, 97\% purity) and yttrium nitrate hexahydrate (Alrich, $99.9 \%$ purity) are dissolved in ethyl acetate to obtain a clear solution [18.3 $\mathrm{cm}^{3}$ of aluminum tri-sec-butoxide and $16.65 \mathrm{~g}$ of $\mathrm{Y}\left(\mathrm{NO}_{3}\right)_{3} \cdot 6 \mathrm{H}_{2} \mathrm{O}$ dissolved in $50 \mathrm{~cm}^{3}$ of ethyl acetate separately and then mixed and stirred for $30 \mathrm{~min}]$. The mixture is exposed to microwaves in a glass beaker using a domestic microwave oven (Batliboy eddy, Thrissur, India, operating at $2.45 \mathrm{GHz}$ and maximum output power of $500 \mathrm{~W}$, in steps of $100 \mathrm{~W}$ ) set at its maximum power level. In under $30 \mathrm{~s}$ evolution of bubbles occurs, and in under $15 \mathrm{~min}$ the solution becomes increasingly viscous, white, and heterogeneous. Brown fumes are seen during the initial stages of drying of the viscous solution. In under 20 min a fluffy dry white mass is formed in the beaker, which is the precursor powder coded as YAG-AP. The white mass feels like talcum powder when pressed between fingers. In the second stage, YAG-AP powder 
was transferred into an alumina crucible and heated at $15^{\circ} \mathrm{C} / \mathrm{min}$ in a conventional furnace (Thermolyne 46100, Dubuque, Iowa) up to $1000{ }^{\circ} \mathrm{C}$. In a different set of experiments, samples were withdrawn from the furnace at various temperatures for recording their x-ray diffraction (XRD, Cu $\mathrm{K}_{\alpha}$, Jeol-JDX 8P, Nagakami, Tokyo, Japan) patterns and infrared spectra (FTIR, Perkin-Elmer, Spectrum 1000, Beaconsfield, UK). In the third stage, YAG-AP calcined at $1000{ }^{\circ} \mathrm{C}$ for $1 \mathrm{~h}$-code named as YAG-CPwas pelletized using $1 \%$ PVA as binder and at a load of $50 \mathrm{kN}$ in a uniaxial press. The $10-\mathrm{mm}$-diameter, approximately $3-\mathrm{mm}$-thick pellets were flanked by $2-\mathrm{cm}$ diameter and 2-mm-thick alumina plates and were placed in a $\mathrm{SiC}$ pit after which it was covered with $\mathrm{SiC}$ powder. It was ensured that $\mathrm{SiC}$ was not in contact with the YAG-CP pellet. The whole assembly was transferred into a microwave reactor (custom built, MES, Bordeaux, France, operating at $2.45 \mathrm{GHz}$, monomode, maximum output power of $2000 \mathrm{~W}$; can be raised in steps of $1 \mathrm{~W}$; reflected microwave power can be read directly) and irradiated with microwaves at a setting of $400 \mathrm{~W}$ for just $35 \mathrm{~min}$. The pellet was allowed to cool, mildly polished on both sides, and examined using illumination from the underside of the pellet. The pellet was found to be reasonably translucent and is code-named YAG-CT. It is possible that lower power and longer exposures also give rise to well-sintered products with different grain sizes. In this work, relations between the exposure time and input microwave power have not been fully mapped along with their microstructures.

The nature of the structural changes occurring in the second stage has been investigated using differential thermal analysis and thermogravimetric analysis (DTA/TGA, Polymer Labs, STA1500, Amherst, MA) of YAG-AP. The combined differential thermal analysis (DTA) and thermogravimetric analysis (TGA) is shown in Fig. 1. TGA indicates a gradual loss of weight of about $15 \%$ around $400{ }^{\circ} \mathrm{C}$. By around $800{ }^{\circ} \mathrm{C}$ the weight stabilizes to approximately $66 \%$ of the original weight. Correspondingly, there is an initial exothermic behaviour

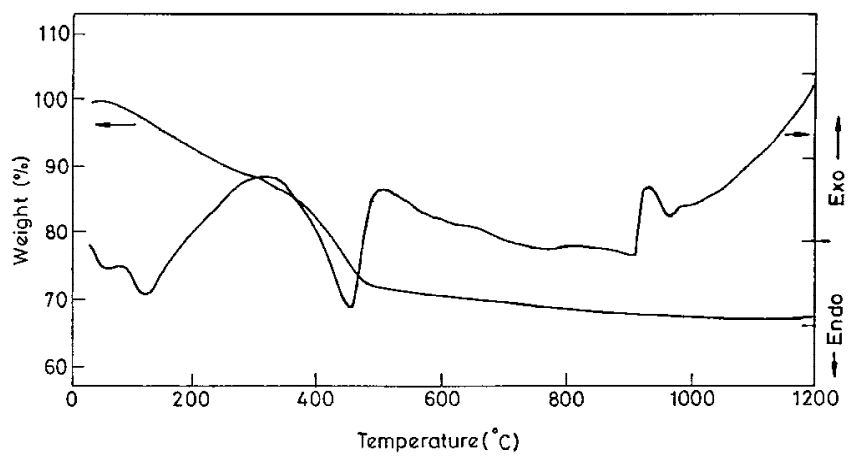

FIG. 1. Combined DTA/TGA of microwave-decomposed precursor YAG-AP. between 150 and $300{ }^{\circ} \mathrm{C}$ followed by a large endotherm between 300 and $500{ }^{\circ} \mathrm{C}$ in DTA coinciding with the region of steplike weight loss in TGA. Around $900{ }^{\circ} \mathrm{C}$ a sharp exotherm is observed, and above $1000{ }^{\circ} \mathrm{C}$ a small and gradual exothermic change is noticed. TGA and DTA observations read together indicate that (i) initial loss of weight up to $300{ }^{\circ} \mathrm{C}$ is associated with the burning of organic matter (exothermic), (ii) steplike change is likely due to the decomposition of nitrates (endothermic), (iii) crystallization around $900{ }^{\circ} \mathrm{C}$ (exotherm) and formation of YAG-CP, and (iv) progressive sintering of the fine particles of YAG-CP above $1000{ }^{\circ} \mathrm{C}$ (mild exothermic behavior). The nature of the decomposition products of the organic matter could not be ascertained. It is possible that the solvents (ethyl acetate and water) evaporated first followed by the decomposition of the butoxide above approximately $100{ }^{\circ} \mathrm{C}$. There were no organic residues left in the powder after decomposition after heating to $1000{ }^{\circ} \mathrm{C}$ in the second stage before compacting the powder for sintering.

The fluffy powder obtained at the end of second stage was X-ray amorphous as shown in Fig. 2(a). It remains so until $900{ }^{\circ} \mathrm{C}$, and above that it rapidly crystallizes, in a single step, to monophasic YAG. No impurity peaks are observed in XRD. Heating up to $1000^{\circ} \mathrm{C}$ is done to confirm that no further changes occurred in the XRD pattern. A 1-h period of calcining is found to be the upper limit for the sintering time to ensure complete crystallization.

The FTIR spectra of the YAG-AP at 30, 900, and $1000{ }^{\circ} \mathrm{C}$ are shown in Fig. 2(b). In YAG-AP it is evident that nitrates are not fully decomposed, as revealed by the absorption peak in the region of $1400 \mathrm{~cm}^{-1} .^{25}$ The $1600-\mathrm{cm}^{-1}$ peak can be attributed to the $\mathrm{C}-\mathrm{O}$ stretching and is due to the unburnt residual organics. At $900{ }^{\circ} \mathrm{C}$, well above the decomposition region observed in DTA/TGA and below the crystallization temperature, there is a broad peak centered on $700 \mathrm{~cm}^{-1}$ with a shoulderlike feature in the region of $600 \mathrm{~cm}^{-1}$. Above $916{ }^{\circ} \mathrm{C}$, well-defined absorption peaks of crystalline YAG (YAG-CP) emerge from the same spectral features as shown in Fig. 2(b). This first stage involves production of the amorphous powder with atomically homogeneous dispersion of reactants. The nitrate in the amorphous powder however decomposes to a small extent (brown gas is observed to evolve) even at $140{ }^{\circ} \mathrm{C}$ during microwave irradiation. The second stage involves the decomposition of both the organic components and the nitrate in the same order, leading to the formation of amorphous YAG powder. The powder crystallizes at $916^{\circ} \mathrm{C}$.

The scanning electron microscopy (SEM) (JEOL JSM-5600LV, Nagakami, Tokyo, Japan) image of YAG$\mathrm{CP}$ recorded from a sample heated at $1200{ }^{\circ} \mathrm{C}$ after ultrasonication is shown in Fig. 3. It is evident that the 


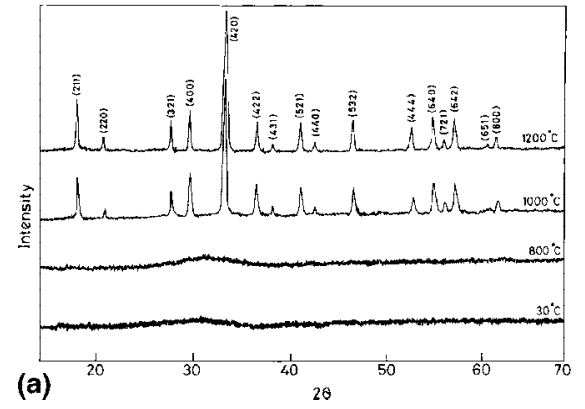

(a)

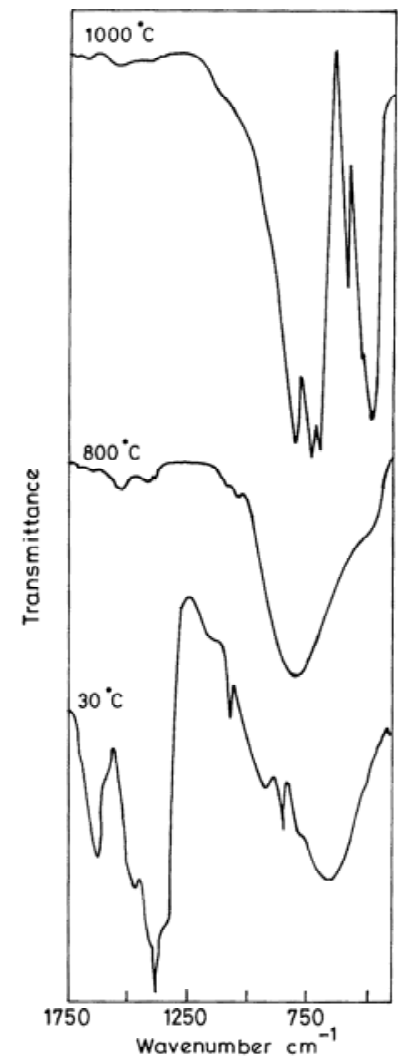

FIG. 2. (a) X-ray diffraction pattern of YAG-AP at 30, 900, and $1000{ }^{\circ} \mathrm{C}$. (b) FTIR of YAG-AP at 30, 900, and $1000{ }^{\circ} \mathrm{C}$.

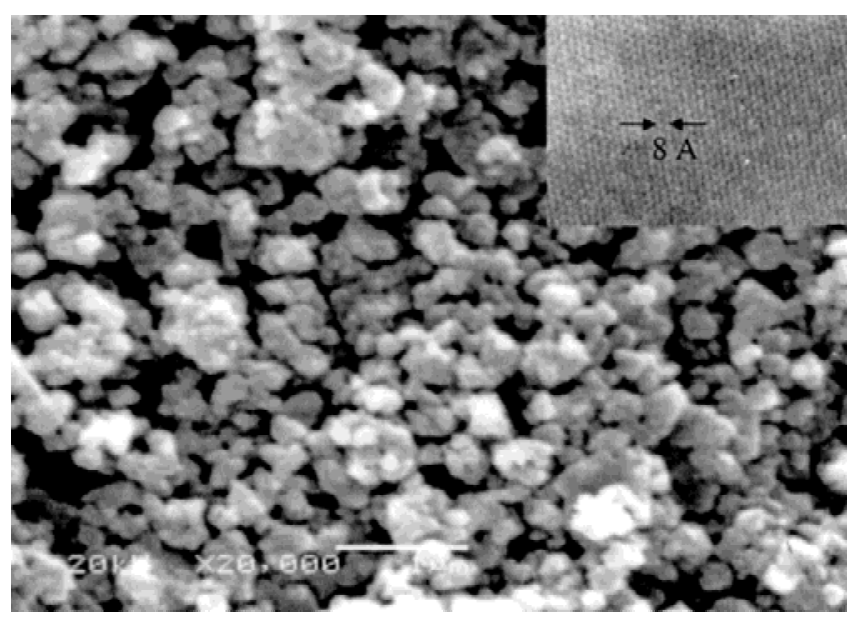

FIG. 3. SEM image of YAG-CP and HREM image of one of the particles is shown as an inset. particulates before crystallization are of submicron size (approximately $100 \mathrm{~nm}$; sub-boundaries) and in the region of $1000-1200{ }^{\circ} \mathrm{C}$ sintering of the particles begins to occur, leading to exothermic behavior noted in the DTA in this region (Fig. 1). The high-resolution electron microscopic (HREM, JEOL 200CX, Nagakami, Tokyo, Japan) image of a particle is shown as an inset in Fig. 3. The interfringe distance is $8 \AA$ corresponding to (110) interplanar distances in cubic structure of YAG, which has a large unit cell (space group $=I a 3 d, a=12 \AA$ ). The sintering is completed in under $35 \mathrm{~min}$. The pellet achieves a maximum temperature of $1350{ }^{\circ} \mathrm{C}\left( \pm 20^{\circ} \mathrm{C}\right)$, in about $15 \mathrm{~min}$, which is measured using an optical pyrometer after carefully removing the top $\mathrm{Al}_{2} \mathrm{O}_{3}$ cover plate. It is known from the work of Jerzy Krupka and co-workers ${ }^{26}$ that dielectric loss $(\tan \delta)$ of the YAG increases rather rapidly as a function of temperature and the rise is exponetial in the region of $720^{\circ} \mathrm{C}$ and above. We attribute this as the reason for the escalating coupling of YAG to microwaves and the consequent rapid increase in temperature which results in a very fast sintering of YAG. It may be noted that the $\mathrm{Al}_{2} \mathrm{O}_{3}$ cover plate was thinly covered with $\mathrm{SiC}$. The pit-wall thickness was much lower than what is required to reduce the microwave intensity to an insignificant level at the sample site. A photograph of the microwave-sintered translucent YAG-TC pellet of very high density $(99.18 \%$ theoretical density) obtained in the third stage is shown in Fig. 4. A 0.86-mm-thick pellet has approximately $45 \%$ transmission at a wavelength of $520 \mathrm{~nm}$. Freshly cleaved surface of the microwave sintered YAG, shown in Fig. 5(a), clearly reveals the absence of any enclosed porosity and is suggestive of the formation of large faceted grains in the sintered body. This may be compared with [Fig. 5(b)] the microstructure of the conventionally sintered sample $\left(1400{ }^{\circ} \mathrm{C}\right.$ for $2 \mathrm{~h}$ ), which reveals clear distinguishing features of neck formation, higher porosity, and grain sizes.

The mechanical properties were studied using the Vickers indentation technique (Zwick 3212, Ulm, Germany). Microhardness ( $H_{\mathrm{V}}$, at a load of $4.9 \mathrm{~N}$ for $15 \mathrm{~s}$ ) was found to be $18.1( \pm 0.3)$ GPa consistent with similar reports. ${ }^{27}$ The fracture toughness $\left(K_{\mathrm{IC}}\right.$, at a load of $58.9 \mathrm{~N}$ for $15 \mathrm{~s})$ was however found to be high, $4.3( \pm 0.2)$

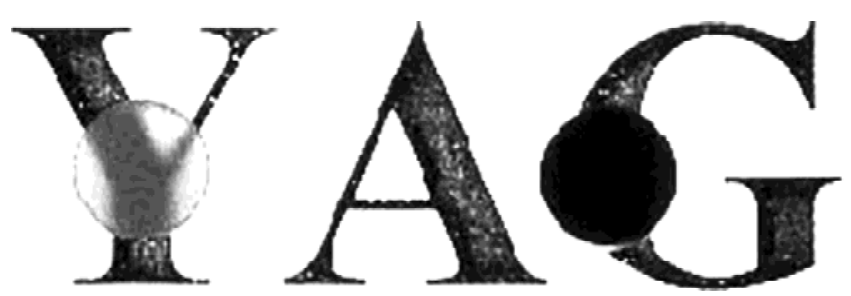

FIG. 4. Photograph showing the contrast between microwavesintered, translucent and conventionally sintered $\left(1400{ }^{\circ} \mathrm{C}, 4 \mathrm{~h}\right)$, opaque YAG samples. 


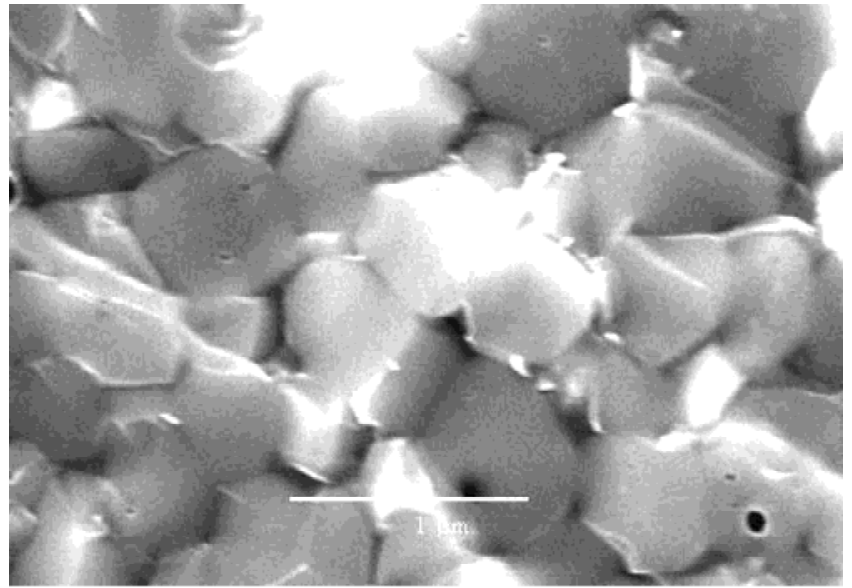

(a)

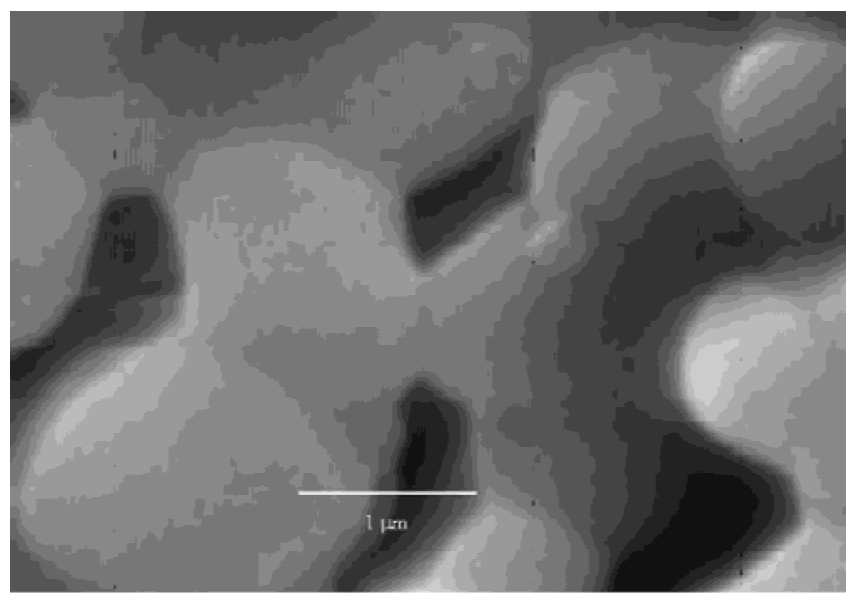

(b)

FIG. 5. (a) SEM image of a freshly cleaved surface of microwavesintered YAG. (b) SEM image of a freshly cleaved surface of conventionally $\left(1400{ }^{\circ} \mathrm{C}\right.$ for $\left.2 \mathrm{~h}\right)$ sintered YAG.

$\mathrm{MPa} \mathrm{m}^{1 / 2}$. This value of $K_{\mathrm{IC}}$ is very reproducible (repeated 4 times). The fracture energy was calculated to be $27.7 \mathrm{~J} \mathrm{~m}^{2}$, which is also consistent with earlier reports. ${ }^{27}$ The $K_{\text {IC }}$ observed by us is perhaps the highest reported for YAG at room temperature. We feel this to be a consequence of the high degree of sintering of the essentially nanometric particles obtained by microwave route. The sintered pellet appeared like a quasi-monolith of high translucency. We feel that the crack propagation in the microwave sintered YAG is likely to occur by an intergranular mode, which accounts for the higher $K_{\text {IC }}$ values as is often understood. ${ }^{27}$

The whole process of preparation of translucent YAG, using microwaves, took under $3 \mathrm{~h}$ from start to finish.
Indeed, the second stage of heating in a conventional furnace can also readily be carried out, in just a few minutes, in microwaves using a secondary heater (not discussed here). This novel microwave-assisted route for the synthesis and processing of YAG eliminates the need for the use of hot pressing, vacuum and sintering aids and has an enormous potential for application.

\section{REFERENCES}

1. J.E. Geusic, H.M. Marcos, and L.G. Van Uitert, Appl. Phys. Lett. 24, 182 (1964).

2. B. Cockayne, J. Less-Common. Met. 114, 199 (1985).

3. T.A. Parthasarathy, T.I. Mah, and K. Keller, J. Am. Ceram. Soc. 75, 1756 (1992).

4. G.S. Corman, J. Mater. Sci. Lett. 12, 379 (1993).

5. S.M. Sim, K.A. Keller, and T.I. Mah, J. Mater. Sci. 35, 713 (2000).

6. J.G. Li, T. Ikegami, J.H. Lee, and T. Mori, J. Am. Ceram. Soc. 83, 961 (2000).

7. M.K. Cinibulk, J. Am. Ceram. Soc. 83, 1276 (2000).

8. R. Manalert and M.H. Rahaman, J. Mater. Sci. 31, 3453 (1996).

9. G. de With and H.J.A. van Dijk, Mater. Res. Bull. 19, 1669 (1984).

10. J.G. Li, T. Ikegami, J.H. Lee, and T. Mori, J. Am. Ceram. Soc. 83, 961 (2000)

11. K.J. Rao, B. Vaidhyanathan, M. Ganguli, and P.A. Ramakrishnan, Chem. Mater. 11, 882 (1999).

12. P.D. Ramesh and K.J. Rao, Adv. Mater. 7, 177 (1993).

13. M. Panneerselvam and K.J. Rao, Adv. Mater. 12, 1621 (2000).

14. W.H. Sutton, Am. Ceram. Soc. Bull. 68, 376 (1989).

15. D.M.P. Mingos and D.R. Baghurst, Chem. Soc. Rev. 20, 1 (1991).

16. D.R. Baghurst, A.M. Chippindale, and D.M.P. Mingos, Nature 332, 311 (1988).

17. J.H. Booske, R.F. Cooper, and S.A. Freeman, Phys. Rev. Lett. 74, 2042 (1995).

18. B.G. Ravi, P.D. Ramesh, N. Gupta, and K.J. Rao, J. Mater. Chem. 7, 2043 (1997).

19. I. Warshaw and R. Roy, J. Am. Ceram. Soc. 42, 434 (1959).

20. J.S. Abell, I.R. Harris, B. Cockayne, and B. Lent, J. Mater. Sci. 9, 527 (1974)

21. G. Gowda, J. Mater. Sci. Lett. 5, 1029 (1986).

22. J.J. Kingsley, K. Suresh, and K.C. Patil, J. Solid State Chem. 87, 435 (1990).

23. M. Inoue, H. Otsu, H. Kominami, and T. Inui, J. Am. Ceram. Soc. 74, 1452 (1997).

24. K.T. Pillai, R.V. Kamat, V.N. Vaidya, and D.D. Sood, Mater. Chem. Phys. 44, 25 (1996).

25. C.N.R. Rao, Chemical applications of infrared spectroscopy (Academic Press, New York, 1963), p. 352.

26. J. Krupka, K. Derzakowski, M. Tobar, J. Hartnett, and R.G. Geyer, Meas. Sci. Technol. 10, 387 (1999).

27. G. de With, High Tech Ceramics, edited by P. Vincenzini (Elsevier Science, Amsterdam, The Netherlands, 1981), pp. 2063-2075. 